University of Warwick institutional repository: http://go.warwick.ac.uk/wrap This paper is made available online in accordance with publisher policies. Please scroll down to view the document itself. Please refer to the repository record for this item and our policy information available from the repository home page for further information.

To see the final version of this paper please visit the publisher's website. Access to the published version may require a subscription.

Author(s): L . Beckford, M . Broome

Article Title: Ethics and the payment of research subjects

Year of publication: 2007

Link to published version: http://dx.doi.org/10.1016/j.mppsy.2006.11.001

Publisher statement: None 


\title{
Ethics and the Payment of Research Subjects.
}

Louisa Beckford and Matthew R. Broome.

\begin{abstract}
:
Subjects, both healthy controls and patients, are reimbursed for their participation in research. This payment is referred to as inducement and medical ethicists consider inducement to be undue if it can lead to the subject not adequately considering the risks to themselves of taking part in the research or if they withhold information about themselves so as to meet the inclusion criteria for the study. Research has found that higher levels of payment do not necessarily lead subjects to disregard the risks of research, but can lead to them withholding information. Psychiatric patients taking part in research may present special difficulties. Therapeutic misconception is common among psychiatric patients and some psychiatric patients may lack the capacity to consent to take part in research.
\end{abstract}

Keywords: inducement, research ethics, subject payment, consent, capacity, therapeutic misconception.

\section{Introduction:}

As a psychiatrist, taking part in research is essential to one's career progression (Philpot 2004). Due to the nature of illnesses psychiatrists investigate, much of our research has 
to be on human subjects. Should one offer such subjects' financial inducement to take part in research? Given the rewards of successfully undertaking research for the investigator, and the possible risk to subjects who take part, ethical issues naturally arise.

\section{Ethics and psychiatric research}

Traditionally, medical ethics has been governed by four principles. These are: nonmalificence, respect for an individual's autonomy, beneficence, and justice. Guided by such principles, all NHS research applications are examined by local and multi-centre research ethics committees.

\section{Payment of research subjects}

Payment of research subjects is commonplace in all medical research. One of the main ethical concerns about paying research subjects is that monetary payment may encourage people to take part in research without properly considering the risks of doing so. This and other ethical considerations will be examined in this article.

\section{Guidelines on paying research subjects}

Ethics committees allow payment of subjects taking part in research, but the guidelines are non-specific. Guidelines usually state that researchers can pay subjects to ensure that they are not made 'out of pocket’ by taking part in research. This means providing 
subjects with cash payment to cover expenses such as travel, meals, loss of earnings etc. Ethics committees also usually require that payment is set at a level which would not unduly influence subjects. However, the level of payment that would constitute this is not specified. Research has shown that the practice of paying research subjects is extremely variable, both across different research institutions and within the same institution (Fry et al. 2005).

\section{Ethical considerations on paying research subjects}

As mentioned, one of the principal concerns about paying research subjects is that if the level of payment is set too high, then subjects might be unduly influenced to take part in the research without fully considering the risks they might be exposing themselves to. Ethicists use the term 'inducement' to describe monetary payment offered to research subjects. Concern arises when an inducement is seen as 'undue'. This can mean that the magnitude of the payment is sufficient to invalidate the informed consent of the subject, by biasing their reasoning such that they underestimate the risks to themselves for example, or that the offer of money is so tempting that subjects might conceal important information about their health in order that they are allowed to take part in the research. Some authors have suggested that payment should only be offered when the research involves very low levels of risk (McNeill 1997).

Another concern is more scientific in nature: offering money to research subjects might differentially recruit those from a more disadvantaged demographic. This might then 
lead to selection bias in the subjects taking part in the study and generate problems in the generalizability of the findings.

Other authors have argued in favour of paying research subjects (Wilkinson and Moore 1997). Payment is also sometimes seen as necessary in research when recruitment is difficult: here it functions as a motivation to encourage subjects to take part in research.

Paying healthy research subjects is sometimes seen as less of a concern than paying patients for taking part in research. It has been suggested that patients should be paid in the same way as healthy subjects as research on both groups involves similar commitments (Dickert et al. 2002), and thus financial inducement is equal for both classes of subjects and determined by the expenses they are likely to incur and the time it may take to undertake the research. See Figure 1.

Figure 1 about here.

\section{Research into paying subjects}

Studies have looked at the willingness of subjects to take part in research and how money might influence this (Bentley and Thacker 2004). Higher levels of payment didn't seem to affect the subjects appreciation of the risks involved in the research. However, money did seem to influence whether or not the subjects might conceal information. The authors suggest that this may affect the findings in studies with low levels of risk to subjects. 
Other studies have replicated this finding (Halpern et al. 2004). This study did find, however, that payment seemed to more strongly influence wealthy subjects' decision to agree to participate in medical research, a finding somewhat contrary to what might have initially been predicted.

\section{Different models of paying research subjects}

Payment could be offered as a monetary incentive to take part in research, although this may be perceived as inducement by ethicists. Another model is to pay subjects for their time and effort, i.e. a 'wage'. A relatively simple way of paying subjects is to offer reimbursement for any expenses incurred e.g. lost earnings, transport costs incurred etc. Yet another model suggested is to offer payment as a standard reward or token of appreciation. See Figure 2.

Figure 2 about here.

\section{Special concerns regarding psychiatric patients}

Psychiatric patients may be a special case. A comprehensive review of the ethics of schizophrenia research has recently been published in the literature (Dunn et al. 2006). There are concerns that some people suffering from schizophrenia may not be able to fully understand the potential risks of taking part in research. Similar concerns exist for other patients e.g. those suffering from dementia. Thus, patients may lack the capacity to 
consent to take part in research. However, although such patients may be vulnerable, some authors have suggested that incapacitated patients should not be prevented from taking part in research. To do so may only serve to increase stigmatization of psychiatric patients and limit research to those who have milder or less severe illnesses.

The issue of therapeutic misconception in psychiatric patients taking part in research is a serious concern. Research has shown that the phenomena may be quite prevalent among psychiatric patients. Patients may believe that by taking part in research, they will obtain enhanced care and treatment. This effect may be enhanced when the researcher and clinician are one and the same individual. In this case, given the inevitable power relationship between psychiatrist and patients, particularly those formally admitted under the 1983 Mental Health Act, the clinician has to ensure that they do not necessarily interpret willingness to take part in research as a sign of clinical improvement, and hence grounds for reducing the level of support and management the individual may be receiving. The over-riding duty of a clinician taking part in research with patients, whether that patient is one's own or not, is to the patient's health, safety, and well-being: and this duty needs to be conceptualized as the risk of potential harm to the subject who takes part as balanced against the gain to the individual and society from the research in question

\section{Conclusion}


The recruitment and payment of research subjects can generate substantial ethical dilemmas for the psychiatrist. There are the pressures to complete research quickly and efficiently, and to include a wide range of subjects. These are in tension with the duty to not worsen a patients' health, either psychological or physical, nor to compromise their capacity to consent to the study by undue inducement or by the expectation of clinical benefit. It is these latter obligations ultimately that must guide the clinician in their actions as a researcher.

\section{Acknowledgement:}

We would like to thank Dr Michael Philpot for his helpful comments on an earlier version of this paper. 
Figure 1 Advantages and disadvantages of paying research subjects.

Advantages:

Better recruitment

Possibly higher retention rate

Subjects recognized/ rewarded for taking part

Subjects do not suffer financially

\section{Disadvantages:}

Possibility of undue inducement of subjects

Payment may bias subject selection

Little consistency between studies

Subjects may expose themselves to risks

Possibility of exploitation of vulnerable groups

Figure 2 Proposed models of payment of research subjects (adapted from (Grady 2005).

- 'Market' model - payment given as an incentive to take part.

- 'Wage' model - reimbursement for time. 
- Reimbursement model - payment for expenses incurred.

- 'Reward' model - expression of thanks for taking part. 
References:

Bentley, J. P., and Thacker, P. G. The influence of risk and monetary payment on the research participation decision making process. Journal of Medical Ethics (2004) 30:293-298.

Dickert, N., Emanuel, E., and Grady, C. Paying Research Subjects: An Analysis of Current Policies. Annals of Internal Medicine (2002) 136(5):368-373.

Dunn, L. B., Candilis, P. J., and Weiss Roberts, L. Emerging Empirical Evidence on the Ethics of Schizophrenia Research. Schizophrenia Bulletin (2006) 32(1):47-68.

Fry, C. L., Ritter, A., Baldwin, S., et al. Paying research participants: a study of current practices in Australia. Journal of Medical Ethics (2005) 31:542-547.

Grady, C. Payment of clinical research subjects. The Journal of Clinical Investigation (2005) 115(7):1681-1687.

Halpern, S. D., Karlawish, J. H. T., Casarett, D., et al. Empirical Assessment of Whether Moderate Payments Are Undue or Unjust Inducements for Participation in Clinical Trials. Archives of Internal Medicine (2004) 164:801-803.

McNeill, P. Paying People to Participate in Research: Why Not? Bioethics (1997) 11(5):390-396.

Philpot, M. An introduction to ethics of research in psychiatry. Psychiatry (2004) 3(3):26-29.

Russell, M. L., Moralejo, D. G., and Burgess, E. D. Paying research subjects: participants' presepctives. Journal of Medical Ethics (2000) 26:126-130.

Wilkinson, M., and Moore, A. Inducement in Research. Bioethics (1997) 11(5):373-389. 